\title{
Assessing Doping Prevalence is Possible. So What Are We Waiting For?
}

\author{
Roger Pielke Jr. ${ }^{1}$
}

Published online: 5 October 2017

(C) Springer International Publishing AG 2017

How many? This is one of the most important questions to ask and answer in any policy-making setting. How many immigrants live in the UK [1]? How many people have polio [2]? How many Bluefin tuna are caught each year [3]?

Effective management or regulation in any policy setting would not be possible without an ability to answer such questions. "How many?" is easy to ask, but in many cases, it can be fiendishly difficult to answer. Often, empirical research using multiple methods are necessary to determine a useful answer, and even then estimates can be clouded by uncertainties and areas of fundamental ignorance.

The question of how many? is just as important to answer in the context of anti-doping (prohibitions against the taking of certain banned substances) in elite sport [4]. Fortunately, the accurate quantification of the number of athletes who dope presents no more complicated a methodological challenge than counting British immigrants, those afflicted with polio, or the number of fish in the sea. In fact, it's probably much easier to answer.

However, for reasons both scientific and political, it has proven difficult to develop robust estimates of the number of elite athletes who take banned performance-enhancing substances. In a 2015 review, De Hon et al. [5] observed, "Remarkably, few scientific articles have addressed this subject so far, and the last review dates to 1997. As a

This commentary refers to the article available at: https://doi.org/10. 1007/s40279-017-0765-4

Roger Pielke Jr.

pielke@ colorado.edu

1 Sports Governance Center, CU Athletics, University of Colorado, Boulder, CO, USA consequence, the true prevalence of doping in elite sports is unknown." There are of course understandable reasons for sports organizations to wish to remain ignorant about the prevalence of doping. As a World Anti-Doping Agency (WADA) Working Group concluded in 2012, "There is no general appetite to undertake the effort and expense of a successful effort to deliver doping-free sport" [6].

In their review, De Hon et al. [5] recommended the use of a survey technique called the "randomized response technique" (RRT), which allows the athlete to maintain both anonymity of his/her identity and his/her answer. Lensvelt-Mulders et al. [7] concluded that "using randomized response questions in surveys on sensitive topics significantly improves the data quality of the surveys. Currently available research has not demonstrated the superiority of any data collection method to RRT." Despite almost a half-century of the use of RRT methods to elicit data on sensitive topics, until now there has been only one study to apply RRT to doping prevalence [8], which found that $20-39 \%$ of German Olympic-level athletes admitted to using banned substances in the previous year.

The publication by Ulrich et al. [9] in this journal, presents a second empirical study of doping prevalence using RRT. This is a very important paper for at least three reasons:

- First, it offers addition empirical evidence on the prevalence of doping in elite sport.

- Second, the journey that the paper took from initial commissioning to publication illustrates the challenges of conflicts that sport organizations face in anti-doping.

- And third, the paper provides a clear proof-of-concept for the implementation of an evidence-based approach to documenting the prevalence of doping in elite sport.

Let's briefly consider each in turn. 


\section{Prevalence}

Ulrich et al. conducted two random-response surveys in 2011 of 2167 athletes participating in (a) the International Association of Athletics Championships in Daegu, South Korea and (b) the 12th Quadrennial Pan-Arab Games, held in Doha, Qatar. The results of this survey are, in a word, stunning.

They find $43.6 \%$ (with a $95 \%$ confidence interval of $39.4-47.9 \%$ ) of surveyed athletes at the International Association of Athletics Federations (IAAF) 2011 World Championships admitted to taking banned performanceenhancing substances and 57.1\% (95\% CI of 52.4-61.8\%) of surveyed athletes at the 12th Quadrennial Pan-Arab Games. In a round number that summarizes the findings of the two surveys, Ulrich et al. provide evidence that about $50 \%$ of elite athletes doped at two major athletics events of 2011. ${ }^{1}$ One in two athletes is a big number, and suggests that doping is truly endemic in elite sport.

\section{The Journey}

Readers of this study might note that the research was conducted in 2011, yet publication in a peer-reviewed journal is only occurring now, some 6 years later. Academic publishing can be slow, but in this instance the delay was the result of the sports organizations that oversaw and funded the study, the IAAF and the World Anti-Doping Agency [10].

Rolf Ulrich, the lead author, explained in 2016 to a parliamentary inquiry in the UK that "WADA had made an agreement with IAAF which was not disclosed to the research group. According to this agreement, WADA would need permission from IAAF in order for us to submit the paper" [11]. Not only did IAAF and WADA refuse to allow the paper to be published, but according to Ulrich [11], top IAAF officials made "several misleading and incorrect claims" about the research, including a false claim that the paper had failed peer review. As controversy developed over the paper's publication, WADA had its authors retroactively sign a confidentiality agreement [11].

Modern science is replete with examples of organizations with conflicts of interest interfering with research. Sport is no different. The journey taken by this study from its commissioning and ultimate approval by WADA and IAAF to its eventual, delayed publication 6 years later in this journal highlights the importance of independent

\footnotetext{
1 There were 76 Russians included in the 2167 athletes surveyed. Even if all the Russians were a part of the alleged Russian doping scheme that has been investigated in recent years, that would still leave more than 1000 dopers among the surveyed athletes. Clearly, doping is not just a Russian problem.
}

research, conducted independently of sports organizations (including WADA), to maintain scientific integrity.

\section{Proof of Concept}

Quite apart from the results and the journey, the paper by Ulrich et al. is important because it demonstrates that robust data on doping prevalence can be collected in a realtime competition setting. It would be straightforward for such data to be collected at every elite sporting event. The costs are low, requiring several tablet computers and individuals to administer the surveys to each athlete. Such data collected could be included as a required and expected part of athlete registration at elite events.

Of course, provisions would need to be put into place to ensure data integrity and independence of the data collection from sport organizations such as IAAF, and equivalent organizations for other sports, and WADA. The exact details on data collection, analysis and integrity would have to be worked out, but Ulrich et al. indicate that these hurdles can be overcome to produce rigorous estimates of doping prevalence.

Perhaps the most important result from Ulrich et al. is not that half of elite athletes are doping, but rather quantifying prevalence and how it changes over time is not just possible, but readily available. Anti-doping agencies, sport organizations and the athletes whom they oversee simply have to decide that gathering such data is a priority. So what are we waiting for?

Sport will not begin to confront its doping problem until asking and answering "how many?" becomes a priority.

\section{Compliance with Ethical Standards}

Roger Pielke, Jr. declares that he has no conflict of interest. No financial support was received for the preparation of this manuscript.

\section{References}

1. Hawkins O. Migration statistics, house of commons briefing paper, number SN06077. 2017. http://researchbriefings.files. parliament.uk/documents/SN06077/SN06077.pdf. Accessed 11 Sept 2017.

2. World Health Organization, Polio eradication initiative. http:// polioeradication.org/. Accessed 11 Sept 2017.

3. Food and Agricultural Organization, Fisheries statistical collections: global tuna catches by stock. http://www.fao.org/fishery/ statistics/tuna-catches/en. Accessed 11 Sept 2017.

4. Pielke R Jr. Gather data to reveal true extent of doping in sport: drug cheats will not be tackled properly until anti-doping agencies do more to assess the scale of the problem scientifically. Nature. 2015;517(7536):529-30.

5. de Hon O, Kuipers H, van Bottenburg M. Prevalence of doping use in elite sports: a review of numbers and methods. Sports Med. 2015;45(1):57-69. 
6. Pound R, Ayotte C, Parkinson A, Pengilly A, Ryan A. Report to WADA executive committee on lack of effectiveness of doping programs. 2012. https://www.wada-ama.org/sites/default/files/ resources/files/2013-05-12-Lack-of-effectiveness-of-testing-WGReport-Final.pdf. Accessed 11 Sept 2017.

7. Lensvelt-Mulders GJ, Hox JJ, Van der Heijden PG, Maas CJ. Meta-analysis of randomized response research: thirty-five years of validation. Sociol Methods Res. 2005;33(3):319-48.

8. Pitsch W, Emrich E, Klein M. Doping in elite sports in Germany: results of a www survey. Eur J Sport Soc. 2007;4(2):89-102.

9. Ulrich R, Pope HG, Cléret L, Petróczi A, Nepusz T, Schaffer J, Kanayama G, Comstock RD, Simon P. Doping in two elite athletics competitions assessed by randomized-response surveys. Sports Med. 2017. doi:10.1007/s40279-017-0765-4.

10. Rohan T. Antidoping agency delays publication of research, New York Times. 2013. http://www.nytimes.com/2013/08/23/sports/ research-finds-wide-doping-study-withheld.html. Accessed 11 Sept 2017.

11. Ulrich R. Letter to Right Honorable Jesse Norman, Member of Parliament. 2016. http://www.parliament.uk/documents/commonscommittees/culture-media-and-sport/Correspondence/Letter-fromUniversity-of-Tubingen-regarding-blood-doping-11-January-2016. pdf. Accessed 11 Sept 2017. 